\title{
DEVELOPMENTS ON ELECTRIC VEHICLES AND ITS FUTURE
}

\author{
Ricky Johnson Ganta \\ Department of Mechanical engineering \\ Student \\ ICFAI Foundation for Higher Education \\ Hyderabad
}

\begin{abstract}
The current paper deals with development of the electric vehicle which will be beneficial for future scope. The battery should be operated at the safe temperatures. Low temperatures or high temperatures can be problematic for the life of the battery as well as the operating of the battery. The commonly used battery is lithium ion battery and it need to be operated at optimal temperatures for efficient operation and maximum lifespan of the battery. This study is about the working of an electric vehicle how it uses the battery to power the vehicle and the parts used to power the vehicle. This study also includes the developments in electric vehicles recently. This paper also describes the comparison between the parts and components in electric vehicles. The major components are battery technology, charger design, steering system, motor technology and braking. The recent developments in the electric vehicles have been shown in this paper and the future of electric vehicles in upcoming years are also been shown in this paper.
\end{abstract}

Problem Definition: Charging of Electric Vehicles takes very long time compared to the internal combustion engine which requires only to a minute to refuel the vehicle. Battery weight is heavier compared to the fuel. Cost of the battery is very expensive. Price of the electric cars are expensive compared to internal combustion cars. Some customers find electric car problem to rely. Market is low for electric cars.

\section{INTRODUCTION}

Electric vehicles working with the help of the electricity stored inside a battery. These are environmental friendly unlike combustion engines these electric vehicles do not produce exhaust gases into the environment. But these electric vehicles must be charged from some renewable sources. For example the energy produced from a wind powered electricity, hydroelectric power and biogas power producing plants. Basically the power from the battery is sent into the electric motor which produces power to move the vehicle. The controller sends the power from battery to the parts further. The controller also sends the power required amount depending upon the acceleration which we give with the help of a pedal inside the car. Here the electric energy is converted into mechanical energy. In the year 1830

\author{
Avinash Malladi \\ Department of Mechanical engineering \\ Faculty of Science and technology \\ ICFAI Foundation for higher education \\ Hyderabad
}

the first electric carriage has been built. In the year 1891 the first electric automobile has been built by United states of America. Now the best company that manufactures the electric vehicles is Tesla motors which is built by Elon musk a famous entrepreneur and a private developer. The first car which Tesla manufactured is Tesla model s which has a range of 300 miles which is $485 \mathrm{~km}$ which has an acceleration of $0-60 \mathrm{mps}$ in 2.5 sec which is impressive.

Ramesh.C.Bansal(2005) examined on "Electric Vehicles", Battery pack which is the heart of the electric vehicle and generates the energy and fabricated the collision in the components of an I.C Engine and also known as zero emission vehicles. Since there was absence of tail pipes and no chance of combustion taking place in the engine so they are called as environment friendly vehicles. The paper mainly focused on the Battery Management System and applicable in the aerodynamics and safety. Su.Y.Cho(2010) focused on "Recent Trends in the development of online vehicles". He categorized the wireless vehicle systems into two different parts followed by Vehicle Powered Roadways and Stationary Powered Roadways. The power transmission depends on capacity, efficiency of the vehicle, electromagnetic flux, weight of the vehicle and wireless transmission. Naoki Shinohara(2013) studied on "Progress on Wireless Power Transmission for Electric Vehicles". Wireless Power Transmission is the transfer of the electrical energy from the power source to an electric load without the interconnection of wires. It has the ability to charge the electric vehicles. They divided into two categories followed by Inductive Coupling and Resonance Coupling . Inductive coupling utilises magnetic fields for observing the movement of current through the wires. Bending of the wire into coil amplifies the magnetic field. Resonance coupling used in the computers, laptops and Mobiles. Chaokri Mahamoudi (2014) investigated on "Overview of electric vehicles and power management strategies". Electric vehicles can be driven either in the single source or in the multiple sources. He implemented various methodologies for getting the optimum results. The vehicles can be classified into three categories on the basis of power management Battery Vehicles, Hybrid Electric Vehicles and Range Electric Vehicles. Hybrid Electric system is applicable at low speeds and used in the city traffic systems. Range Electric vehicle have low consumption of the fuel and 
high capacity in the jet propulsion vehicles. Sergio Manzetti(2015) examined on "Electric Vehicle Battery Technologies from present status to future generations" Electric vehicles associated with emission of greenhouse gases. Increase in the greenhouse gases lead to excess of power sources in the automobile vehicles in some countries. With the application of chemicals and fuels in the battery for restoration of power without any error and beneficial in the transport sector. The future scope can occur in the development of Hybrid Electric vehicles. Yash Lethewala(2018) focussed on "Development of Automotive Hybrid Electric System". He has discussed about current status of hybrid electric vehicle and to shift towards electrification of vehicles. He developed the Two wheel converter in the experimental manner which converts petrol wheel vehicle into hybrid electric vehicle.

\section{HEV'S AND EV'S}

Hybrid electric vehiclesare also extensively used in the automobile market. Everyone company manufactured at least one HEV. HEV uses both electric power as well as fuel to power the vehicle. HEV'S are of two types which are series HEV and parallel HEV. In series HEV the engine uses the electric power totally

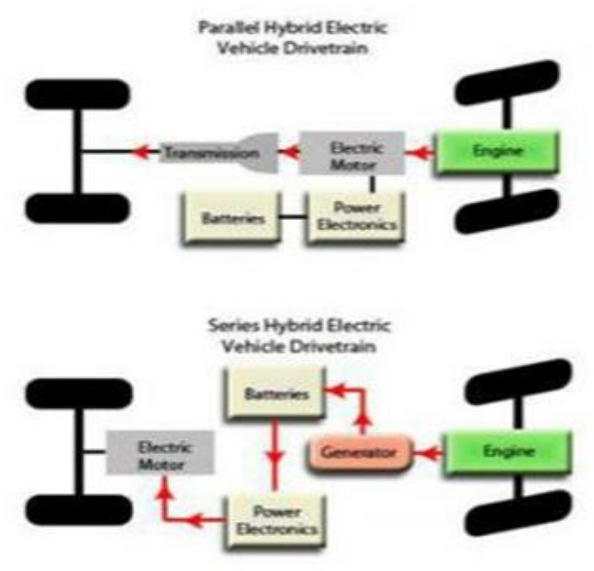

Figure- 1 Difference between the series and parallel HEV'S

All the motor power is consumed from the battery. In parallel HEV both battery power as well as engine power are utilized. The torque produced is the combination of the battery power and engine power. But HEV uses internal combustion engines which pollute the environment but are comparatively less which IC vehicles does. The plug in hybrid vehicle is introduced and developed for more convenient use.

\section{The motor}

There are 5 types of motors available

\section{Dc motors}

This a classic motor which is being used for a long time. All the power which is produced in the electromechanical conversion is transferred to the rotor through stationary brushes that are in rubbing contact with the copper segments of the commutator. It requires maintenance and it has shorter life span. It has power level which is less than $4 \mathrm{~kW}$.

\section{Induction motor}

This is a popular AC motor. Which is vastly used in air conditioning, escalators etc. which has more than $5 \mathrm{~kW}$ power.

\section{Dc brushless motor}

This motor is mechanically low because of lower power winding. It has longer life span but it is expensive.

\section{Permanent magnetic synchronous motor}

This stator is similar to induction motor. This rotor is mounted to permanent magnets. The driving voltage is the sine wave generated by the pulse width modulation (PWM)

\section{Switched reluctance motor}

It is variable reluctance machine. This has a fault tolerance because each phase is decoupled from others. Each phase winding is connected into a fly back circuit style.

Selection of the proper motors is done by the performance requirements of the vehicle. For an example for go karts and golf vehicles requires less than $3 \mathrm{~kW}$ motors. For high performance vehicles such as 4 wheelers, buses etc. The ideal motor is PMSM or induction motor.

\section{Direct drive and in wheel motor}

The direct drive reduces the loss in mechanical units of the drive train. This motor is connected directly to the shaft to reduce need of transmission, the clutch and the gear box. The researchers recently prompted the in wheel motor. This motor is to turn the rotor inside out and attach tonthe wheels rim and the tire.

This motor is called also as a wheel hub motor. Its main advantage is to control each wheel independently. Each wheels works at any speed and at any direction.

Japanese developers recently developed worlds first in wheel motor system. It transmits the power wirelessly to run motors in each wheel. 


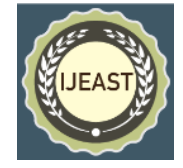

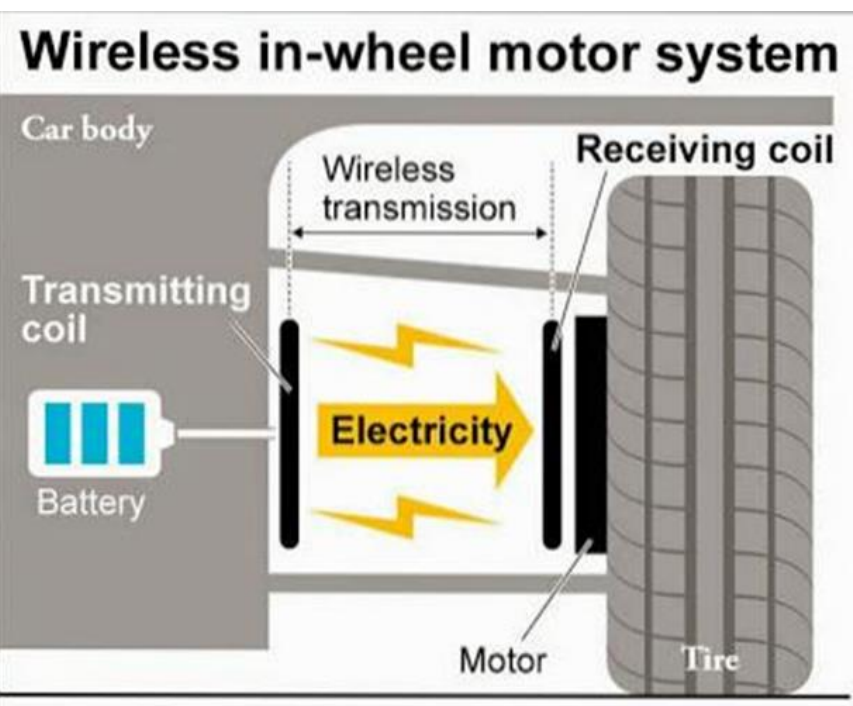

Figure-2 Wireless motor system in Wheel drive

\section{Battery}

Battery is the main source for the storage of electric energy in the vehicle. Recently there are many researches have been done and the battery Li-ion is used for the new generation electric vehicles. Some batteries are unstable and so many studies have been conducted. LIFEPO4 is preferred because it is chemically stable and inherently safe. Due to its low cost lead-acid battery are used currently in market. More researches are being conducted to improve fast charging in batteries. Recent studies of MIT reported crystal structure technology which allows 100 times of charging speed than conventional Liion batteries. Ultra capacitors also can be used as alternative.

\section{Ultra capacitors}

The capacitors are static components. No chemical reaction takes place in them. The charging and discharging speeds are quick. But the energy storage is limited which is less than $20 \%$ of the lead acid battery. Ultra capacitors will be used in the coming years but main energy storage should be a challenge.

\begin{tabular}{|c|c|c|c|c|c|}
\hline $\begin{array}{c}\text { S.n } \\
\text { o }\end{array}$ & Parameter & $\begin{array}{c}\text { Lead } \\
\text { Acid } \\
\text { Batter } \\
\text { y }\end{array}$ & $\begin{array}{c}\text { NiM } \\
\mathrm{H}\end{array}$ & $\begin{array}{c}\text { Li-ion } \\
\text { Cltra } \\
\text { Capacito } \\
\text { rs }\end{array}$ \\
\hline 1. & $\begin{array}{c}\text { Energy } \\
\text { Density(Whr/ } \\
\text { kg) }\end{array}$ & 40 & 70 & 110 & 5 \\
\hline 2. & $\begin{array}{c}\text { Working } \\
\text { Temperature( } \\
{ }^{\circ} \text { C) }\end{array}$ & $\begin{array}{c}30 \sim+5 \\
0\end{array}$ & $\begin{array}{c}40 \sim+5 \\
0\end{array}$ & $\begin{array}{c}40 \sim+6 \\
0\end{array}$ & $-40 \sim+85$ \\
\hline 3. & Cycle Life & 500 & 800 & 1000 & 500000 \\
\hline 4. & Cost(KW/hr) & 1000 & 2400 & 1000 & 50000 \\
\hline
\end{tabular}

Table-1 Comparison of Different Energy Storage Levels
So ultra capacitors are used for fast speed or transient energy storage. Because it allows high current charging, its charging time can be shortened for a few minutes. Researchers are still developing the ultra capacitors and it is still in the initial stages. So it is expected the cost will be cheaper and the energy density will be increased rapidly in the upcoming years.

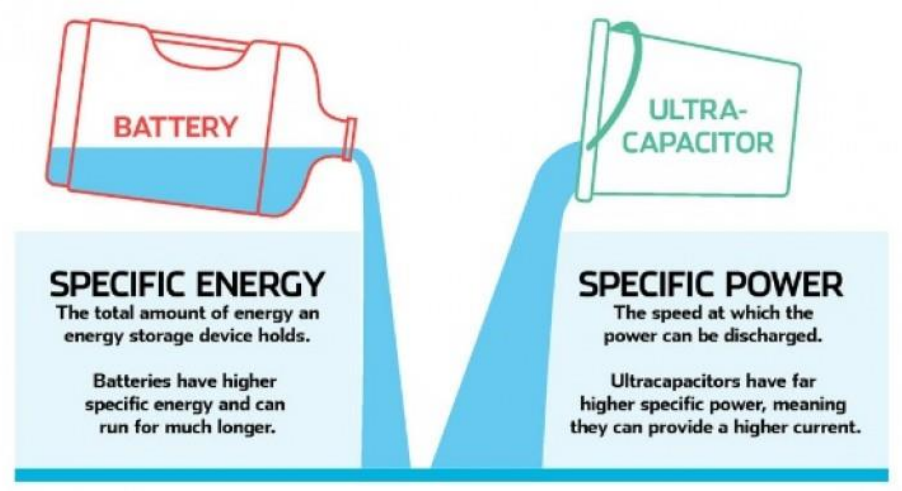

Figure-3 Difference between Battery and Ultra Capacitor

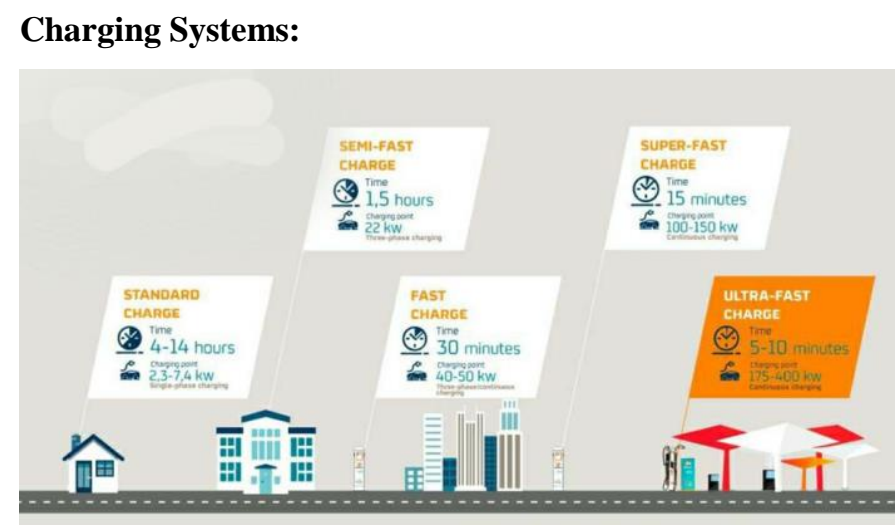

Figure-4 shows the Charging times of different types of charging

The charger used for the battery weather it may be slow charger or a fast charger it should handle high power. The power converter such as $\mathrm{H}$-bridge is required. This converter gives good efficiency and applications in charger and DC-DC converter.

The developments are done on fast changing and by controlling the connector-pin temperature at high current draws, and decreasing the current draw by upping the voltage.

For example The above figure of charging time shows the development on the charging of the battery. 


\section{Battery management system}

It is additionally referred as BMS. The battery system is created by variety of battery ells. they're connected in parallel or series that's in keeping with the look. every of the cell ought to be watching and controlled. The acquisition watching includes the voltage, current and temperature. The measured parameters square measure wont to offer the choice parameter for the system management and protection. 2 parameters square measure typically provided. they're the state of charge (SoC) and therefore the State of Health ( $\mathrm{SoH}) . \mathrm{SoC}$ is just like the oil tank meter that gives the battery charging condition. it's measured by the knowledge of voltage and current. The so is to record the health or aging condition.

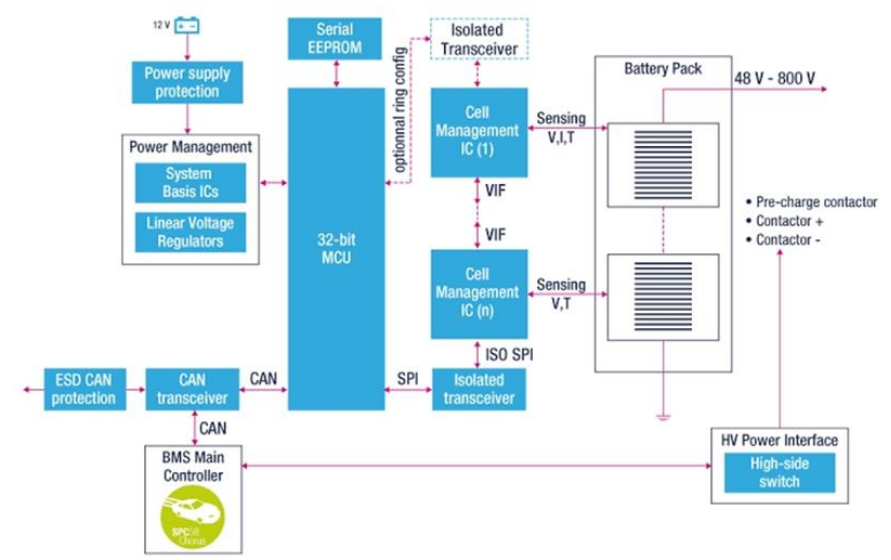

Figure-5 Schematic Diagram of Battery Management System

$\mathrm{SoH}=$ Nominal capacity - loss of capacity / nominal capacity .

\section{Charging networks}

The charging time of the battery is shorter in the recent development. The lead acid battery charging rate is less than $0.2 \mathrm{C}$ and quick charging of it can seriously reduce its lifetime. $\mathrm{Li}$-ion battery has a recommended $0.5 \mathrm{C}$ charging rate.

Nowadays most of the electric vehicles have onboard chargers in them. Which can be connected to the power source and the vehicle. So charging stations should provide more power points.

\section{Fast charging stations}

A high current is needed for fast charging so three phase power is generally used. So charging stations must consider the method to connect the three phase socket because most people cannot handle three phase sockets.

\section{Magnetic contactless charging}

The power transfer is done through magnetic induction. There is no metal contact. So this reduces the trouble when a person handling the power socket so that he/she doesn't require to contact the socket.

\section{High voltage power transfer}

The big sized 3 phase socket and cable can be shrunk in size by high voltage connections. The power source can be stepped up to reach high voltage of more $\mathrm{kV}$ so the cable is reduced.

\section{Battery rental}

The battery rental can also be done. The electric vehicles must be manufactured such a way that the battery can be replaced in the rental places when the user battery gets discharged so that it can be swapped with the fully charged ones. This also helps to reduce the tine taken by charging the battery.

\section{Braking and steering system}

Disc brakes are used in vehicles which is a mechanical system. But in case of electric vehicles both electrical and mechanical braking must be used. The electrical power regeneration braking should be applied. Generally when deceleration or going down on a slope the kinetic energy produced can be returned to the battery. So energy can be saved and safety is provided.

\section{Anti locking braking system}

Anti locking braking system is used to prevent skidding of the vehicle and to provide stable braking to the vehicle. The braking depends on the tyre performance and road conditions.

In regenerative braking, once an automotive has to be braked, the motor is turned within the reverse direction, or if the motor is associate ac motor, it's then operated within the third quadrant of operation. The effect is that the motor currently acts as a generator and provides energy back to the battery. In some cases, this energy could also be hold on in some different storage systems quickly, like flywheel, spring systems etc.

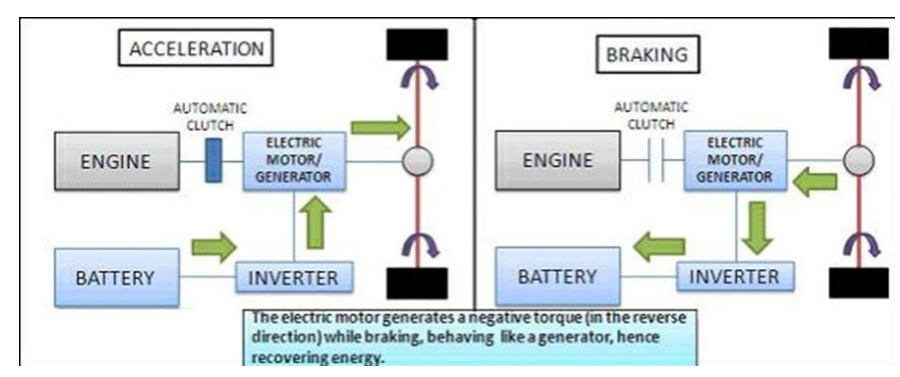

Skid steering

Steering is achieved by totally differentially varied the speeds of the lines of wheels on different sides of the vehicle so as to 
induce yaw. To satisfy the necessity of the flip radius, the longitudinal slip should be controlled, thus a technique of slip limitation feedback is employed within the simulation. once the vehicle is popping on a slippery surface, attributable to the drop at the constant of road adhesion, the drive wheels might slip. The traction system reduces the engine torsion and brings the slippy wheels into the desired skid range
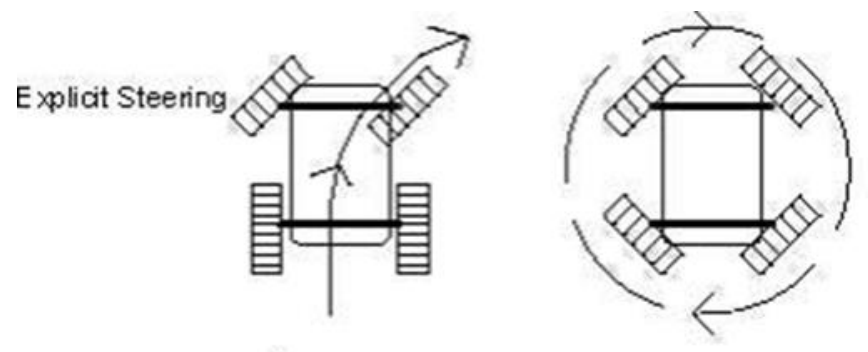

Skid Steering
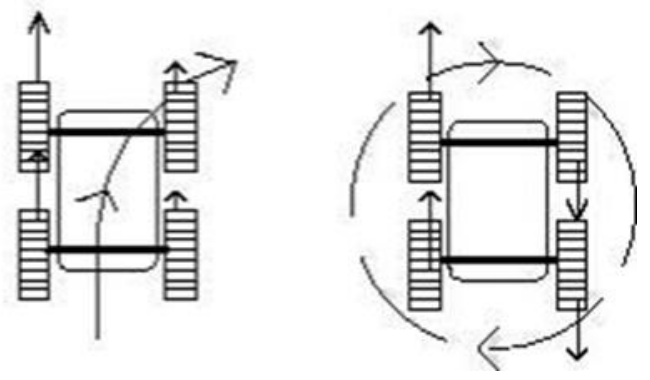

Figure-7 Explicit and Skid Steering

\section{Suspension}

The shock absorbers are used to absorb the shock and bumps on the road and to provide a comfortable ride. These bumps provide up and down motion to the vehicle. They use two cylinders with a small cylinder inside and bigger out side. Sometimes the smaller cylinder is replaced with a spring. So the vertical energy can be captured from the up and down motion to produce electricity.

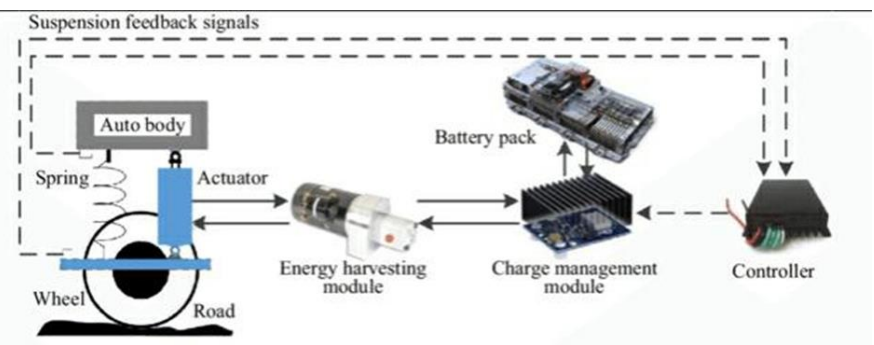

Figure-8-Regeneration of Steering System

\section{Adaptive front lighting system}

The lighting system is based on LED (light emitting diode) and adaptive front lighting system. Is security system in the vehicles. The functions of an adaptive front lighting system is divided into three parts which are headlamp levelling subsystems, which keeps the light in parallel to the road surface when the vehicle tilt changes in static and dynamic mode. The second one is swivelling subsystem which provides best illumination for the driver by matching light distribution with the vehicles turning angle. The third one is the dimming system which dims or fades the light with ambient lighting and lane environment changes.

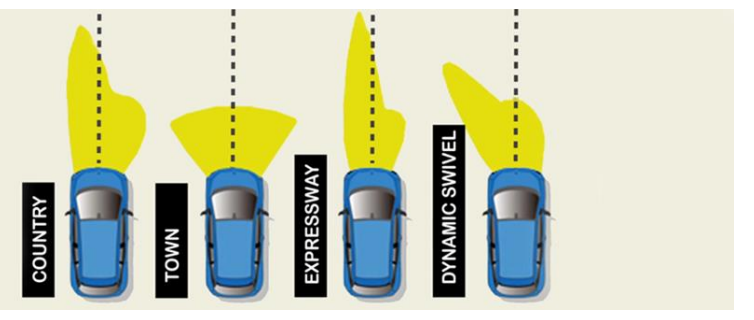

Figure-9- Adaptive Front Lighting System

\section{Future of electric vehicles}

From surveys conducted the electric vehicles market is projected to reach 26,951,318 units by the year 2030. Currently an estimated of 3,269,671 units of electric vehicles are in the year 2019. The electric vehicle market is going on developing rapidly in automotive sector. The government policies and support in terms of subsidies and grants, tax rebates and nonfinancial benefits like car pool lane access and a new car registration is favourable

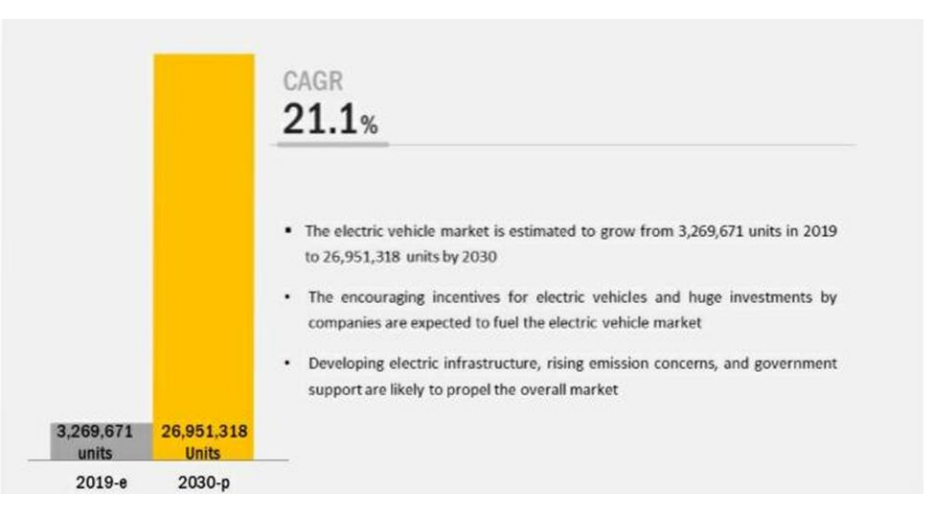

Figure-10 Compound Annual Growth Rate

Due to zero direct emission and various governments are toward a cleaner environment, this has increased the demand for zero emission vehicles. Developed nations such as Germany, United states, and United Kingdom are actively promoting the uses of electric vehicles to reduce emissions, which has resulted in growing of electric vehicles sales. 


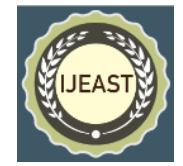

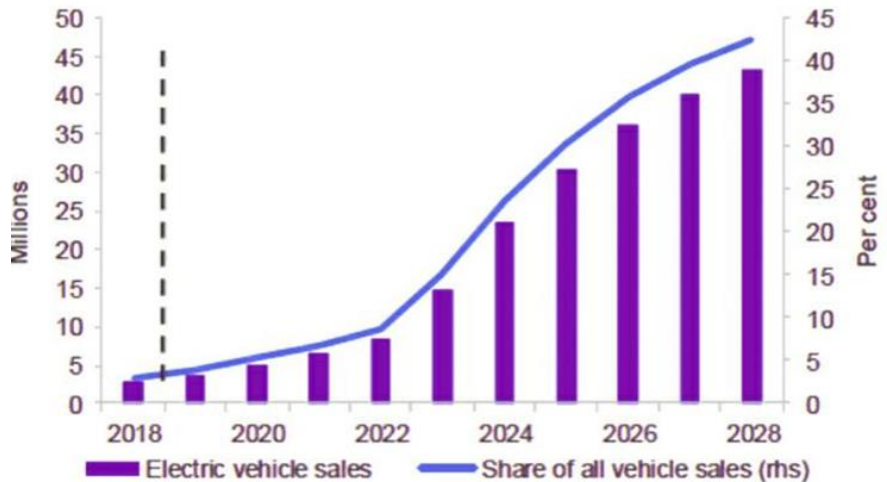

Figure-11 Graph Analysis of Long Term Electric Vehicle Sales

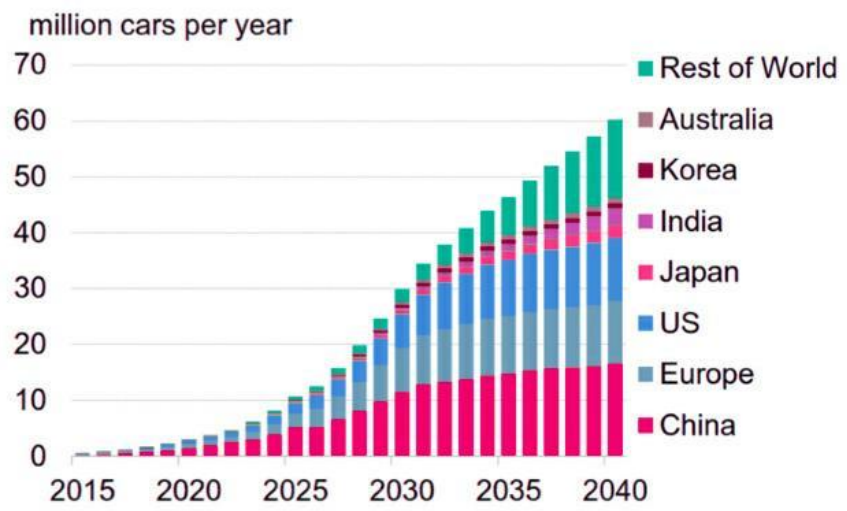

Figure-12 Annual Growth Rate of Electric Vehicles region by region

\section{CONCLUSION}

There are many institutions and companies working for the development of electric vehicles. The development of electric parts, safety and control accessories are reported. This paper describes about the development of the electric vehicle's general structure, energy storage and the future vehicle components. This paper also discusses about the future of electric vehicles worldwide.

\section{REFERENCE}

[1]. Ramesh C. Bansal,"Electric Vehicles”, 2005 by Taylor \&amp; Francis Group, LLC.

[2]. Su Y. Cho,2010 "Recent Progress in Developments of On-line Electric Vehicles", IEEE.

[3]. Naoki Shinohara,2013 "Wireless Power Transmission Progress for Electric Vehicle in Japan", IEEE.
[4]. Dr. Chokri MAHMOUDI, 2014“AN OVERVIEW OF ELECTRIC VEHICLE CONCEPT AND POWER MANAGEMENTSTRATEGIES", IEEE,

[5]. Sergio Manzetti, 2015 "Electric vehicle battery technologies: From present state to future systems"; ELSEVIER,

[6]. YASH LETHWALA, "DEVELOPMENT OF AUTOMOTIVE HYBRID ELECTRIC SYSTEM”, LAMSYS18, ISRO, 2018.

[7]Asif Faiz; Christopher S. Weaver; Michael P. Walsh (1996). Air Pollution from Motor Vehicles: Standards and Technologies for Controlling Emissions. World Bank Publications. p. 227. ISBN 978-0-8213-3444-7.

[8]Guarnieri, M. (2012). Looking back to electric cars. Proc. HISTELCON 2012 - 3rd Region-8 IEEE HISTory of Electro Technology CONference: The Origins of Electrotechnologies. pp. 1-6. doi:10.1109/HISTELCON.2012.6487583. ISBN 9781-4673-3078-7.

[9] mary bellis (16 June 2010). "Inventors - Electric Cars (1890-1930)". Inventors.about.com. Retrieved 26 December 2010 .

[10]Hendry, Maurice M. Studebaker,1972: One can do a lot of remembering in South Bend. New Albany, Indiana: Automobile Quarterly. pp. 228-275. Vol X, 3rd Q,p231

[11]Matthe, Roland; Eberle, Ulrich (1 January 2014). The Voltec System - Energy Storage and Electric Propulsion. pp. 151-176. ISBN 9780444595133. Retrieved 4 May 2014.

[12]Bellis, M. (2006), "The Early Years", The History of Electric Vehicles, About.com, retrieved 6 July 2006 